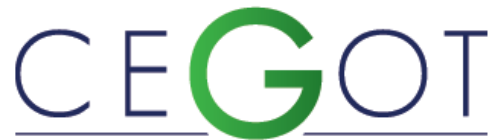

Centro de Estudos de Geografia e Ordenamento do Território
Geografia e Ordenamento do Território, Revista Eletrónica Centro de Estudos de Geografia e Ordenamento do Território http://cegot.org

PRUDÊnCIO, ANA

Universidade de Lisboa, Instituto Superior Técnico, Departamento de Engenharia Civil, Arquitetura e Georrecursos Av. Rovisco Pais, 1049-001 Lisboa, Portugal teresa.prudencio@tecnico.ulisboa.pt

\section{BRANDÃO, ANA}

Universidade de Lisboa, Instituto Superior Técnico, Departamento de Engenharia Civil, Arquitetura e Georrecursos Av. Rovisco Pais, 1049-001 Lisboa, Portugal ana.luisa.brandao@tecnico.ulisboa.pt

\title{
A produção e gestão do espaço público em Portugal
}

\author{
The Public space production and management in Portugal
}

Referência: Prudêncio, Ana; Brandão, Ana (2019). A produção e gestão do espaço público em Portugal. Revista de Geografia e Ordenamento do Território (GOT), n. ${ }^{\circ} 16$ (março). Centro de Estudos de Geografia e Ordenamento do Território, p. 297-322, dx.doi.org/10.17127/got/2019.16.013

\section{RESUMO}

Em Portugal, o interesse e relevância do espaço público no âmbito das políticas urbanas tem vindo a crescer, com o aumento da produção de novos espaços e intervenções em espaços existentes. A par da diversidade de tipologias e contextos, multiplicam-se também os instrumentos de atuação e os atores neles envolvidos com diferentes contributos e interesses. Neste âmbito, a produção de espaço público mostra-se uma matéria complexa e multidimensional, marcadamente contextual, onde se relacionam questões normativas, políticas, financeiras, funcionais e sociais. Este artigo pretende fazer uma discussão sobre a produção e gestão do espaço público em Portugal, fazendo uma análise exploratória desta complexidade, clarificando o quadro normativo relevante e os principais atores intervenientes, com o intuito de identificar os desafios e problemáticas que daí decorrem.

Palavras-chave: Espaço público, produção urbana, gestão do espaço público, atores.

\section{ABSTRACT}

In Portugal, interest and relevance of public space in the scope of public policies has been growing, along with new public spaces production and redesign of existing spaces. Diversity in urban contexts and typologies is matched by multiple planning and design instruments and several stakeholders, each of them with different contributions and interests. In this scope, public space production arises as a complex and multidimensional issue, highly contextual, including regulatory, political, financing, functional and social interconnected issues. This article aims at discussing public space production and management in Portugal, making an exploratory analysis of this complexity, clarifying the relevant regulatory framework and the main stakeholders involved, so as to identify resulting challenges and problems.

Keywords: Public space, production of urban space, public space management, stakeholders. 


\section{Introdução}

Tradicionalmente, considera-se o espaço público como o local da expressão coletiva, de socialização, onde decorre a manifestação cultural e identitária da cidade (Borja \& Muxí 2003), e como um elemento estruturante e organizador do espaço urbano, palco de interação da vivência urbana (Lynch 1960; Jacobs 1961). Nas últimas décadas, o espaço público tornou-se um tema central no debate e nas políticas urbanas, não apenas como elemento "embelezador", mas como um valor urbano em si mesmo, como um catalisador e dinamizador de outros processos (Portas 1987), constituindo-se como um instrumento de ação política e de concretização de políticas sociais, económicas e ambientais (UCLG 2016).

Assiste-se, assim, a uma diversificação das tipologias, escalas de atuação e investimentos realizados, incluindo temas como a requalificação de espaços centrais e comerciais, a valorização de aspetos identitários e culturais, a recuperação ambiental, o redesenho de espaços associados à mobilidade, entre outros. A esta multiplicidade de tipologias e objetivos, acrescem outras transformações - da sociedade em geral, dos paradigmas sociais e económicos, dos quadros de governação territorial, etc. - que se têm refletido e vindo a alterar as formas de produção do espaço urbano (Ascher 2001) e também as lógicas de produção e gestão do espaço público, que se complexificam. De facto, seja como elemento principal de investimentos urbanos, seja como elemento integrado no processo de urbanização, o espaço público é instrumental para a implementação de políticas urbanas, mas é também ele próprio um produto decorrente de um processo e de um contexto de produção próprio.

A produção de espaço público envolve várias componentes: o planeamento, programação e desenho, a execução dos espaços, incluindo também a gestão do espaço público, como "o conjunto de processos e práticas que procuram assegurar que o espaço possa cumprir todos os seus papéis, enquanto gere as interações e os impactos das múltiplas funções, de forma aceitável para os utilizadores" 1 (Carmona, Magalhães, \& Hammond 2008). Aqui, consideram-se as várias componentes da gestão no ponto de vista da regulação, da coordenação, do investimento e da manutenção ${ }^{2}$ (ibidem). Neste contexto, centrar-nos-

\footnotetext{
1 Tradução das autoras.

${ }^{2}$ A regulação da utilização e dos conflitos entre usos (criação de regras de comportamento, de acesso e a sua aplicação); a manutenção (práticas e rotinas, para garantir o bom estado de conservação); o investimento
} 
emos numa vertente física da produção do espaço ${ }^{3}$, embora reconhecendo a sua maior amplitude.

Desde logo, face à complexidade do próprio conceito de espaço público ou à diversidade de interpretações e significados ${ }^{4}$ (Coelho 2014), impõe-se uma sistematização da sua relação com os processos de desenvolvimento urbano que poderão estar na sua origem. A produção de espaço público pode decorrer de um conjunto de instrumentos e procedimentos legais, numa lógica de produção planeada ou programada; mas pode também decorrer das relações mais informais, em que o espaço tenha surgido através de outras lógicas e dinâmicas. São exemplo, os espaços resultantes dos processos de transformação e crescimento da cidade, da evolução histórica dos seus usos e funções e suas iterações ao longo do tempo.

Por outro lado, as práticas e as autoridades públicas de planeamento e gestão, por si só, não dominam a produção e gestão do espaço público, mas partilham formal ou informalmente com aqueles que intervêm, beneficiam, usam e se reconhecem nesses espaços. A ação dos diferentes atores que participam na produção do espaço público é assim marcada por interesses e necessidades distintas (McIndoe et al. 2005), que passam a ser parte do processo. A gestão do interesse público, ou a negociação entre os diferentes interesses, será desta forma, uma manifestação contínua nos processos de governança urbana e do espaço público (Seixas 2013).

É já reconhecido que muitas intervenções no espaço público decorrem de contextos e projetos específicos, onde os interesses, os recursos e as oportunidades se conjugam, enquanto outras dependem de múltiplos instrumentos e regulamentos (e da aparente falta de articulação entre eles) e da ação de vários atores com diferentes responsabilidades de

(recursos materiais e financeiros necessários à manutenção dos espaços); e por fim, a coordenação destas intervenções no espaço público, incluindo a tomada de decisões estratégicas e operacionais sobre a gestão do espaço.

${ }^{3}$ Não sendo aprofundada a sua dimensão social e a produção numa lógica de apropriação pelos utilizadores, a produção do espaço vivido (Lefebvre 1974; Fortuna, Ferreira \& Abreu 1999; Pinto 2015).

${ }^{4} \mathrm{O}$ espaço público é uma noção complexa, de limites pouco claros e disputada por diferentes olhares disciplinares - desde uma questão de propriedade fundiária e jurídica, à esfera pública discutida por Habermas, incluindo as perspetivas morfológicas e outras relacionadas com a sua utilização diversificada. O conceito "espaço público" ganha relevância com a crítica da teoria urbanística do Movimento Moderno, ao afirmar a valorização dos usos sociais e de interação e os significados nos espaços exteriores, embora o próprio crescimento urbano desafie funções estabelecidas e tipologias canónicas que lhe são associadas. Assim, neste artigo fazemos uso de uma noção ampla de espaço público, incluindo os espaços (físicos) de domínio público (ou mesmo coletivo) que contribuam para a vida social e o funcionamento dos tecidos urbanos. 
intervenção no território difíceis de conjugar e articular (Brandão, Brandão \& Ferreira 2017). No entanto, a falta de um estudo integrado sobre as suas práticas de produção e gestão motivaram o aprofundamento desta temática. Entender este contexto - os aspetos que enquadram e condicionam o quadro de produção e gestão do espaço público - torna-se relevante num momento em que instituições internacionais de referência afirmam o espaço público como motor de desenvolvimento urbano sustentável (UN-Habitat 2015).

Assim, procurou-se fazer uma reflexão sobre a produção e a gestão do espaço público em Portugal, suportada pela análise do quadro normativo português para a produção de espaço público, pela identificação dos atores-chave nesse processo e na análise de um caso de estudo. O principal objetivo passa por descrever e compreender a complexidade da produção e gestão do espaço público no contexto português, identificando algumas das problemáticas associadas. Assim, neste artigo pretende-se: (1) identificar os instrumentos e ferramentas existentes que permitem a criação de espaço público, (2) sistematizar os principais atores intervenientes e compreender como se estabelecem as relações entre eles no processo de gestão da produção, e (3) identificar os principais desafios e problemas na prática de produção e gestão do espaço público.

A persecução destes objetivos é feita a partir da discussão da bibliografia mais relevante, da recolha e análise documental e da análise de um caso de estudo - o município de Almada ${ }^{5}$ por forma a ilustrar e compreender as práticas de produção e gestão do espaço público, tendo sido concretizada através do aprofundamento e ilustração das temáticas aqui abordadas. A este trabalho acresce ainda a recolha de testemunhos em oito entrevistas semiestruturadas (ver anexo 1) a profissionais liberais da área do urbanismo e a técnicos municipais quer de Almada, quer de outros municípios portugueses ${ }^{6}$.

\footnotetext{
${ }^{5}$ A escolha deste município como caso de estudo deve-se ao facto de Almada ser um município em que a produção e gestão do espaço público resulta da diversidade de contextos urbanos existentes e da aplicação de um conjunto alargado de políticas e projetos. A análise deste caso de estudo foi objeto de um tratamento mais aprofundado e detalhado, não se esgotando nos resultados e observações apresentadas neste artigo.

${ }^{6}$ Estas entrevistas foram realizadas quer especificamente no âmbito desta investigação, quer no decorrer do projeto de investigação "PSSS. O valor de serviço do espaço público como sistema urbano - uma metodologia de avaliação integrada", em desenvolvimento no CERIS, Instituto Superior Técnico, com o qual esta investigação colabora.
} 


\section{A produção do espaço público em Portugal}

Este primeiro capítulo decorre: (1) da análise documental e do conhecimento empírico dos principais instrumentos que influem a produção de espaço público em Portugal e (2) da identificação dos principais atores intervenientes neste processo tendo como referência o contexto português, fundamentada por uma análise bibliográfica sobre a temática em questão. Em ambas as situações recorreu-se a alguns exemplos sobre o município de Almada para ilustrar o conteúdo analisado.

\subsection{Os contextos de produção - o quadro normativo}

A produção de espaço público integrada em ações de planeamento, programação e desenho, decorre de um conjunto de instrumentos, políticas e práticas que, de forma direta ou indireta, a influenciam (figura 1). O quadro normativo que estabelece esta lógica de produção revela-se bastante complexo, pois além de assentar em vários níveis de atuação, é composto por diferentes tipos de instrumentos, que podem ser de natureza regulamentar ou estratégica.

\section{O QUADRO INSTRUMENTAL PARA A PRODUÇÃO DE ESPAÇO PÚBLICO}

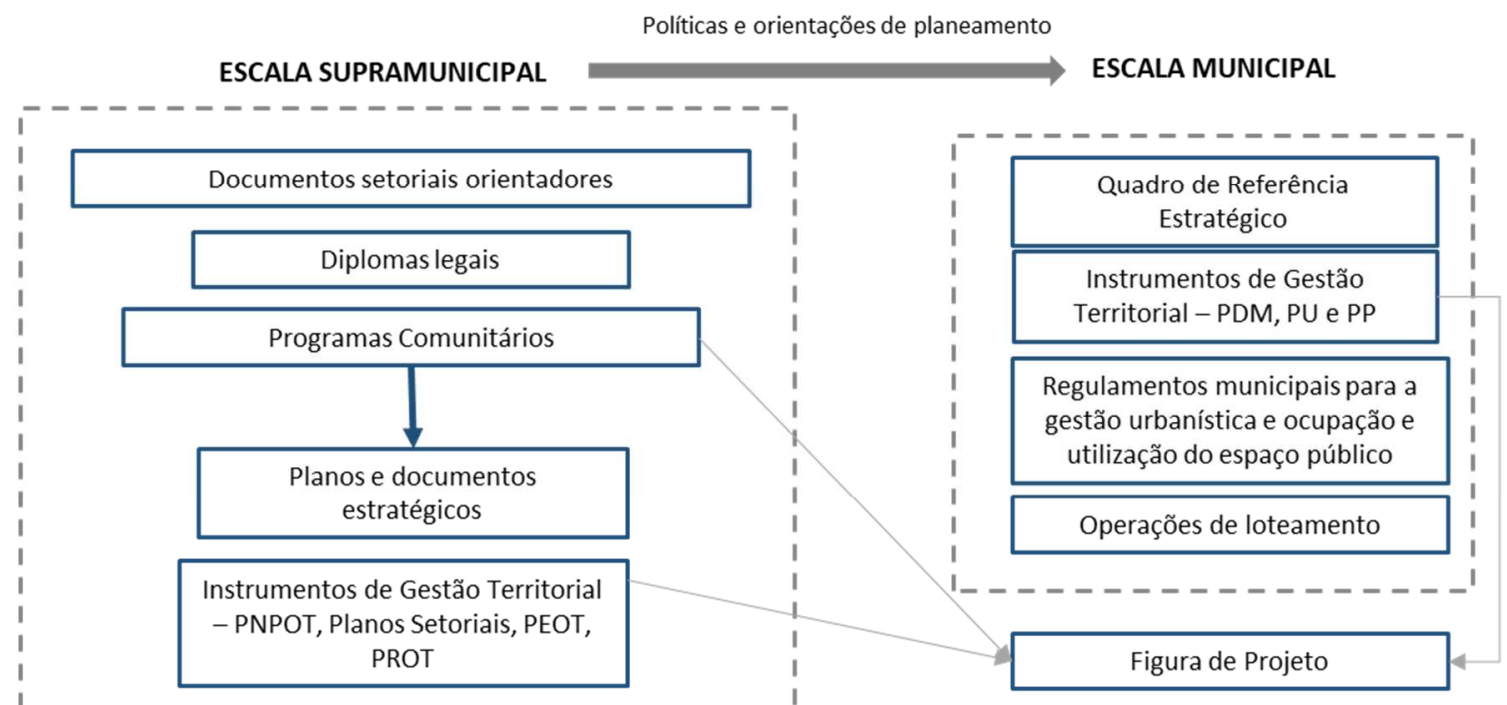

Figura 1. O quadro instrumental para a produção de espaço público em Portugal 
A um nível supramunicipal (escala nacional e regional), a produção de espaço público é influenciada pela existência de documentos orientadores de carácter setorial, produzidos pelos órgãos da Administração e outras entidades públicas, cujo conteúdo influi na conceção do desenho de espaço público ${ }^{7}$ e deve ser integrado nos planos e noutros documentos vinculativos numa escala mais pormenorizada. Ainda neste nível de atuação destaca-se a influência dos programas comunitários que podem conter uma forte componente de intervenção ao nível do espaço público, como o programa PROSIURB $^{8}$, o programa POLIS ${ }^{9}$ (figura 2), as iniciativas comunitárias Urban e Urban $\|^{10}$, os programas de urbanismo comercial como o PROCOM ${ }^{11}$ e o URBCOM $^{12}$, as estratégias e incentivos à regeneração e reabilitação urbana, em especial as Parcerias para a Regeneração Urbana ${ }^{13}$ e mais recentemente os Planos de Ação de Regeneração Urbana ${ }^{14}$. Muitos destes dão origem a documentos e planos estratégicos, que a par de outros $^{15}$, estabelecem orientações e

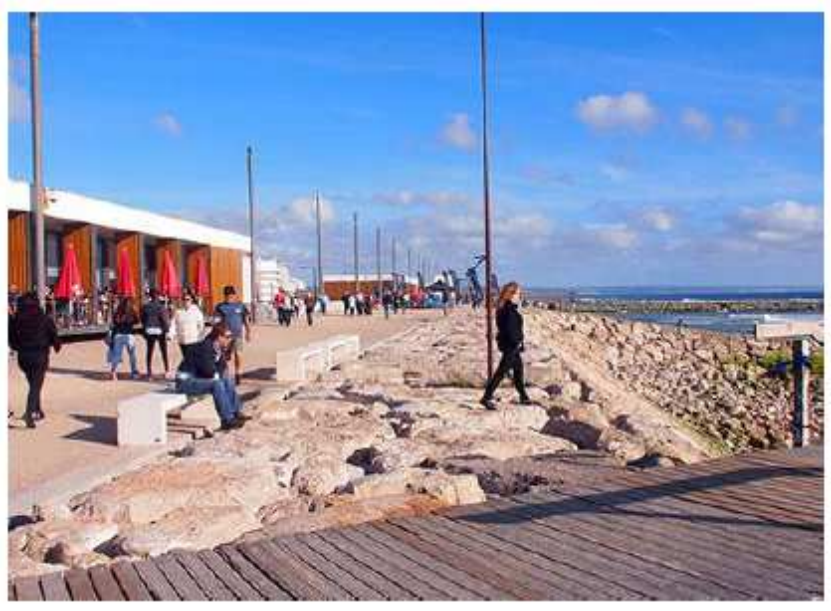

Figura 2. Intervenção do POLIS na Costa da Caparica (Almada) como exemplo de um programa que resultou na produção de espaço público. Fonte própria.

\footnotetext{
${ }^{7}$ Documentos orientadores como o Pacote da Mobilidade (conjunto de documentos que estabelecem o quadro de referência para a abordagem das questões relativas ao território, acessibilidades, transportes e mobilidade, nos quais se incluem orientações para a elaboração de planos de mobilidade e transportes, entre outras) e como o "Ciclando" - Plano para a promoção da bicicleta e outros modos de transporte suave, promovidos pelo Instituto da Mobilidade e dos Transportes (IMT) (http://www.imtip.pt/sites/IMTT/Portugues/Planeamento/DocumentosdeReferencia/Paginas/EstudoseProjectosemCurso.aspx ).

${ }^{8}$ Programa de Consolidação do Sistema Urbano Nacional e de Apoio à Execução dos PDM, orientado para centros urbanos de média dimensão.

${ }^{9}$ Programa de Requalificação Urbana e Valorização Ambiental de Cidades, focado na melhoria da qualidade de vida e requalificação ambiental.

${ }^{10}$ Iniciativas comunitárias que decorreram entre 1994 e 2006 e que tiveram como principal objetivo requalificar e revitalizar as áreas urbanas, centros de cidade e suas periferias.

${ }^{11}$ Programa de Urbanismo Comercial criado em 1994.

12 Sistema de Incentivos a Projetos de Urbanismo Comercial criado em 2000.

13 Instrumento utilizado na aplicação da Política de Cidades POLIS XXI entre 2007 e 2013, destinado a apoiar ações de revitalização integrada de espaços intraurbanos.

${ }^{14}$ Plano com âmbito territorial incidente nos centros históricos, zonas ribeirinhas ou zonas industriais abandonadas, dentro de uma Área de Reabilitação Urbana, que suporta a regeneração urbana.

${ }^{15}$ Como a Estratégia Nacional para a Adaptação às Alterações Climáticas, a Estratégia Nacional para a Gestão Integrada da Orla Costeira, o Plano Estratégico dos Transportes e Infraestruturas, etc.
} 
normas que vão influir indiretamente no espaço público, seja pela área de atuação a que se reportam, seja pela concretização de políticas e estratégias setoriais com incidência territorial. O seu conteúdo deve ser considerado nos instrumentos de planeamento, influenciando a intervenção no espaço público através do cumprimento de objetivos ${ }^{16}$, que se podem traduzir na criação de determinadas tipologias de espaços ou na regulação dos espaços existentes.

À escala supramunicipal existem ainda os Instrumentos de Gestão Territorial, que emanam as principais orientações de planeamento ou de concretização de políticas com expressão territorial. Estes influenciam a produção de espaço público numa escala macro, através da definição das principais prioridades de investimento nacional, das opções estratégicas sobre as áreas de mobilidade, infraestruturas, equipamentos e estruturas ecológicas e ambientais, e da decisão sobre grandes intervenções e projetos.

A produção de espaço público é ainda regulada pelos diplomas legais e outros regulamentos publicados à escala nacional sobre diferentes temáticas que nele incidem e que devem ser consideradas nos planos e projetos. Como exemplo destaca-se o Regime Jurídico da Urbanização e Edificação ${ }^{17}$, cuja influência se estabelece através da regulação das operações de licenciamento da edificação e das operações de loteamento; ou a Portaria n.o 216B/2008 de 3 de março que estabelece os parâmetros para o dimensionamento das áreas destinadas a espaços verdes e de utilização coletiva, infraestruturas viárias e equipamentos de utilização coletiva para os projetos de loteamento.

Por sua vez, a escala de atuação municipal terá também os seus próprios instrumentos: (1) Quadro de Referência Estratégico, i.e., os documentos e planos que definem as estratégias de atuação do município, como os estudos estratégicos territoriais, planos de mobilidade, de acessibilidade, estratégias ambientais, entre outros; (2) Instrumentos de Gestão Territorial e (3) regulamentos municipais, que incidem direta ou indiretamente na produção e gestão do espaço público, como o Regulamento Municipal da Urbanização e Edificação, o Regulamento da Ocupação do Espaço Público, etc.

\footnotetext{
${ }^{16}$ Como a valorização e proteção ambiental, a adaptação e combate às alterações climáticas, ou a promoção da mobilidade sustentável.

${ }^{17}$ Publicado no decreto-Lei no. 555/99, de 16 de dezembro, com décima quarta alteração no decreto-lei n.o 214-G/2005 de 02 de outubro.
} 
A escala municipal será a principal escala de atuação na produção de espaço público, pois reúne todas as orientações e normas definidas a nível supramunicipal, estabelece as grandes opções de planeamento e programação para o espaço público, desenvolvendo os seus próprios projetos, e regula a produção executada por outros atores. Ainda assim, há que considerar a importância dos outros níveis hierárquicos da Administração na produção de espaço público através dos grandes projetos de infraestruturas ou de outras intervenções estratégicas para o território (exemplo do projeto da Expo'98 ou do programa POLIS). Também é de salientar a atuação dos privados neste contexto, através das operações de loteamento por eles empreendidas e da ação dos proprietários nos processos de reconversão de Áreas Urbanas de Génese $|l e g|^{18}$ e nas áreas produzidas sobre outras lógicas e dinâmicas, sem intervenção regulada (ex. núcleos históricos).

O loteamento, enquanto uma das principais figuras da urbanização em Portugal, é uma das principais formas de produção de espaço público à escala local. Através dele, áreas destinadas a espaços verdes e de utilização coletiva, infraestruturas viárias e equipamentos coletivos (áreas de cedência), são obrigatoriamente concedidas pelos promotores, de acordo com os parâmetros estabelecidos pelos Planos Municipais de Ordenamento do Território ou pela legislação constituída para o efeito. Estes mecanismos, embora pretendam salvaguardar o interesse público no âmbito das operações de iniciativa privada, nomeadamente no que respeita à infraestruturação do espaço público e coletivo, apresentam alguns problemas na forma como são aplicados ${ }^{19}$ (Silva 2014), com consequências para o resultado produzido.

Perante este contexto é possível considerar que, no âmbito dos instrumentos de planeamento - sobretudo os de escala macro - e tendo em conta as lógicas de produção urbana em Portugal nas últimas décadas, “ (...) num cenário onde os interesses privados se sobrepõem ao interesse público e onde a ocupação do território se realiza visando o seu maior rendimento" (Coelho 2016), o espaço público surge muitas vezes como elemento

\footnotetext{
${ }^{18}$ De acordo com a Lei n.o 91/95 de 02 de setembro, considera-se uma área urbana de génese ilegal um prédio ou conjunto de prédios que, sem licença de loteamento, tenham sido objeto de operações físicas de parcelamento destinadas à construção.

${ }^{19} \mathrm{Na}$ prática muitas áreas de cedência são residuais, sem significado, que não colmatam as necessidades municipais. Aqui também se verifica uma prática deficitária por parte da Administração, que tem acedido aos interesses privados dos promotores, optando pela não cedência e aceitando as compensações em numerário ou em espécie (Silva 2014), as quais não são facilmente revertidas para a produção de novos espaços públicos.
} 
secundário e na sequência do processo de urbanização (ibidem). Por sua vez, este tem surgido como figura central em instrumentos de planeamento mais detalhados, como os que decorrem de programas já mencionados ${ }^{20}$, sendo mais frequente surgir como elemento principal à escala do projeto, nomeadamente em projetos urbanos, projetos de infraestruturas (figura 3) ou de equipamentos coletivos, ou em projetos específicos de espaço público, a forma mais direta de produção destes espaços.

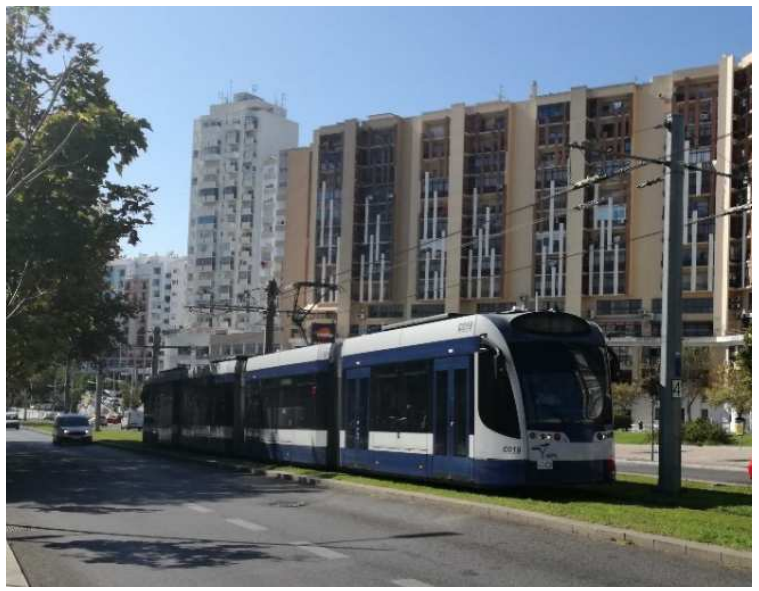

Figura 3. Projeto do Metro Sul do Tejo (Almada) como exemplo de um projeto que produziu espaço público. Fonte própria.

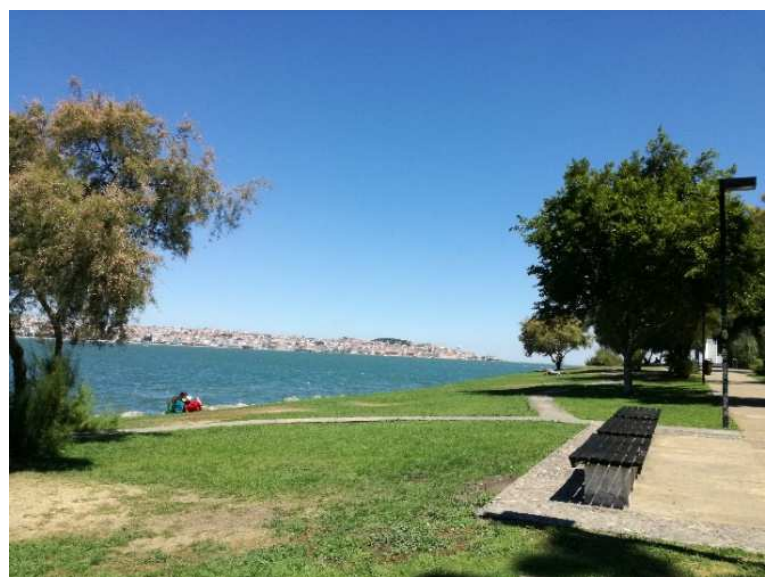

Figura 4. Jardim do Rio - Programa de Reabilitação Urbana "Nova Almada Velha" como exemplo de uma intervenção de produção de espaço público. Fonte própria.

Neste sentido, surgiram nas últimas décadas projetos direcionados para a produção de espaço público, seja numa ótica de requalificação urbana, de construção de infraestruturas ou de valorização ambiental, na sequência das políticas que nortearam a intervenção da Administração Pública, como na revitalização dos centros históricos, na regeneração das frentes ribeirinhas (figura 4) ou na promoção de formas novas de mobilidade.

Muitos destes projetos desenvolvem-se a partir da figura de projeto urbano ${ }^{21}$, utilizado como forma de aproveitar as oportunidades que podem decorrem da disponibilidade de recursos financeiros, de programas comunitários, da ação de marketing político, dos calendários eleitorais (Portas 1998), da organização de grandes eventos ou de novas infraestruturas de exceção (Portas, Domingues \& Cabral 2011).

\footnotetext{
${ }^{20}$ Veja-se o exemplo dos planos de pormenor elaborados no âmbito do programa POLIS ou a requalificação urbana a propósito da Expo'98, concretizada através de um plano de urbanização e de vários planos de pormenor.

${ }^{21}$ Conceito que teve uma aplicação mediática no projeto para a Expo'98, tendo-se replicado posteriormente quase exclusivo a intervenções em espaços urbanos consolidados e dependentes de enquadramentos extraordinários, como a disponibilidade de financiamento ou a forte ação pública (Portas, Domingues \& Cabral 2011).
} 
Considera-se que a produção de espaço público em Portugal tem resultado de intervenções de caráter excecional (projetos especiais, como a Expo'98) e da "produção corrente" de espaço urbano, seja numa lógica integrada de planeamento, seja através de intervenções pontuais, sem uma visão estratégica (operações de pequena e média escala) (Coelho 2016). Estas intervenções são, por vezes, o resultado da aplicação de políticas setorizadas dos municípios, estando o espaço público repartido por vários domínios de intervenção municipal (o planeamento e gestão urbanística, o ambiente, a higiene urbana, a mobilidade, as redes viárias e as infraestruturas, etc.).

Em síntese, entende-se que a produção de espaço público pode surgir a partir de uma das seguintes possibilidades:

- Estratégias nacionais ou regionais que resultem em projetos específicos;

- Planeamento ou programação à escala municipal (por vezes baseada numa visão estratégica, integrada e em rede);

- Projeto concebido à escala local (em intervenções de pequena e média escala);

- Aproveitamento de oportunidades e da disponibilidade de financiamento;

- Integrado na produção urbana corrente, como elemento secundário do processo de urbanização.

\subsection{A governança e os atores na produção do espaço público}

As transformações da sociedade, a globalização e a liberalização da economia refletiram-se na intervenção dos atores na produção urbana, alterando o quadro de governabilidade dos territórios (Brenner 2004). Estamos perante um novo quadro de governança, que é marcado pela diversidade de atores no sistema urbano, pela sua crescente participação no processo de urbanização e pela afirmação dos privados nos processos de produção urbana, em consequência da diminuição da capacidade interventiva e económica do Estado (Healey 2006).

A fragmentação do poder é então um reflexo não só de uma sociedade mais participativa e diversificada, como da própria alteração da estrutura do Estado (Pereira 2009; Brenner 2004). A produção e gestão do espaço público será reflexo de todas estas alterações, caracterizando-se pela heterogeneidade de atores intervenientes, resultado do crescente 
número de atores que desempenham funções no espaço público, da diversidade de organismos envolvidos no processo e da diversidade de espaços existentes. Embora se assuma que a gestão do espaço público seja em feita grande maioria num modelo de Administração Local tradicional (Carmona, Magalhães \& Hammond 2008), na prática muitos aspetos estão fora do controlo direto das autoridades locais, estando as responsabilidades repartidas entre vários atores, públicos e privados - "making places is everyone's job" (Friedmann 2017).

Numa primeira sistematização dos atores que participam diretamente, ou que têm influência, na produção de espaço público, é importante ter em conta as suas motivações, os meios, e os métodos de atuação no objeto de intervenção (Mota 2013). Os atores poderão ter diferentes funções, interesses e formas de influência no espaço público, contribuindo de maneira distinta para a sua produção e gestão, de acordo com os recursos e meios que têm disponíveis e com os quais intervêm.

Tomando como referência o caso português, mas tendo por base as tipologias de atores de Carmona et al. (2003), Carmona et al. (2008) e Mota (2013), identificam-se alguns dos principais atores intervenientes na produção e gestão do espaço público:

- Administração Central (governo e respetivos ministérios);

- Administração Local (municípios e freguesias);

- Outras entidades e institutos públicos (como as Comissões de Coordenação e Desenvolvimento Regional (CCDR), as empresas municipais, as entidades com responsabilidades setoriais (ex. Instituto da Mobilidade e dos Transportes, Agência Portuguesa do Ambiente, Infraestruturas de Portugal, etc.);

- Projetistas i.e., as empresas de planeamento, as consultoras, os urbanistas, arquitetos, arquitetos paisagistas, engenheiros e outros profissionais desta área;

- Promotores, investidores e proprietários imobiliários;

- Concessionários e operadores de infraestruturas e serviços coletivos e outros operadores com ação no espaço público;

- Entidades gestoras de espaços coletivos (equipamentos);

- Utilizadores do espaço público (comerciantes e empresários locais, consumidores de comércio e serviços e trabalhadores locais, residentes, turistas e visitantes, 
associações e organizações de natureza diversa, como as associações de moradores, desportivas, ambientais, comerciais, religiosas, de património, etc.).

Perante a identificação deste conjunto de atores, pode fazer-se desde logo a distinção entre os atores do setor público e do setor privado, aos quais ainda se acrescenta a comunidade. Estes atores terão diferentes competências na produção do espaço, tendo uns uma voz mais ativa neste processo do que outros, o que está relacionado com a sua capacidade económica, política e inter-relacional (Madanipour 2010). Assim, a sua influência no espaço público é exercida de diferentes formas, sendo que o poder se centra nos atores com maior capacidade de intervenção, seja pela ação que têm no desenho ou no projeto, pela iniciativa de produção, pelos recursos que possuem, pela capacidade de promoção ou regulação da transformação do espaço (ibidem). Os atores podem assumir papéis distintos e cumulativos, associados à sua função na produção e na gestão do espaço público - produtor, regulador ou utilizador do espaço.

Neste contexto, distinguem-se os atores promotores da produção de espaço público, do ponto de vista político e técnico: os promotores políticos, enquanto atores que influenciam a tomada de decisão; os promotores técnicos que contribuem para a conceção técnica do plano ou projeto, com o desenho do espaço. O setor público será aqui o principal interveniente, com papel relevante na orientação de políticas, no financiamento da produção e na elaboração de instrumentos urbanísticos e regulamentos que ditam a regulação da transformação e ocupação do espaço. Há ainda que destacar os projetistas, enquanto atores técnicos, e o papel dos promotores imobiliários ou das entidades gestoras dos espaços coletivos que, pela sua capacidade de gerar projetos, podem ser considerados promotores indiretos de espaço público (figura 5).

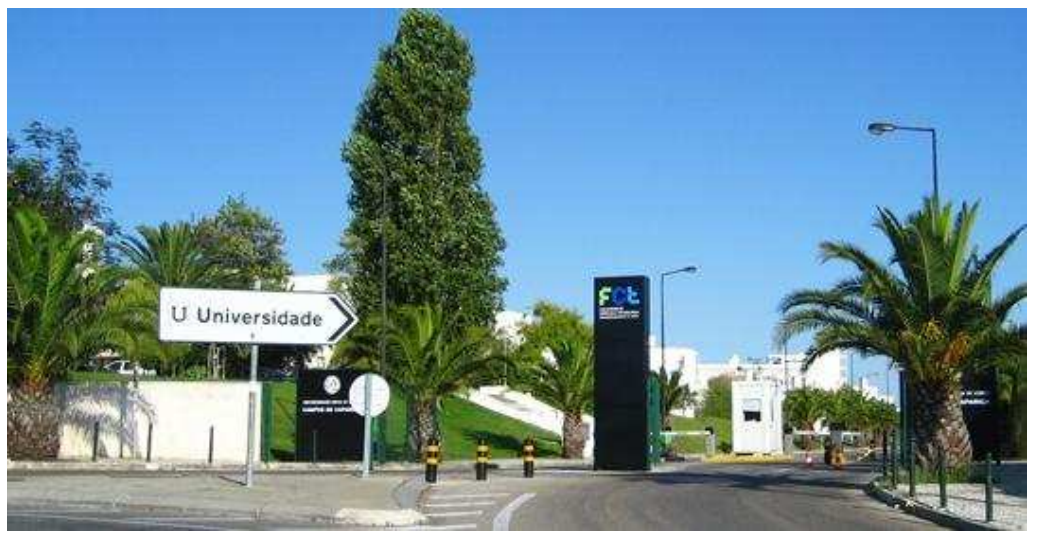

Figura 5. Faculdade de Ciências e Tecnologia - Universidade Nova de Lisboa (Almada) como um exemplo de um equipamento que gerou espaço público. Fonte: site da FCT 
A Administração Local assume-se como um ator com várias esferas de atuação, intervindo na produção de espaço público ao nível do planeamento e programação municipais, na conceção de projetos resultantes dessas ações, na execução desses espaços (ou pelo menos em parte dela) e na sua gestão. São-Ihe atribuídas as funções de mediador de interesses e de facilitador, cabendo-lhe a promoção e regulação das parcerias entre o setor público e privado, a colaboração com outras esferas de governação e assegurar a existência de espaços inclusivos, seguros e de qualidade (UCLG 2016). Neste sentido, enquanto promotor político e técnico, o município é detentor de meios diretos e indiretos para a produção e gestão, nomeadamente (1) poder de decisão, (2) recursos relacionais (i.e., capacidade de mobilização e coordenação de atores), (3) recursos financeiros, (4) competências jurídicas e administrativas para a regulação e fiscalização e (5) conhecimento e recursos técnicos para suporte à tomada de decisão. Enquanto ator político, tem preocupações em responder aos eleitores e grupos de interesses, podendo ver no espaço público um instrumento de concretização de políticas e de propaganda eleitoral.

Numa outra perspetiva, distinguem-se os atores económicos (promotores imobiliários, proprietários, investidores, concessionários e operadores de infraestruturas e serviços coletivos e outros operadores que atuam no espaço público), cuja forma de intervenção assenta numa lógica de retorno financeiro e de valorização económica (Herce 2013). Estes podem constituir-se como atores produtores do espaço público do ponto de vista da execução, contribuindo com diferentes meios para a sua produção: recursos financeiros, propriedade do solo e capacidade de influência na decisão, devido à pressão que podem exercer sobre os atores políticos. Alguns, como os concessionários e operadores de infraestruturas e serviços coletivos, acumulam ainda a função de utilizadores do espaço público - aqui designados por utilizadores comerciais $^{22}$ - partilhando outros interesses e motivações, numa lógica funcional e de qualidade de prestação de serviço. Os operadores que atuam no espaço público (assim como as entidades gestoras de espaços coletivos) podem ainda ter uma importante função de reguladores da utilização do espaço.

No entanto, o domínio do interesse económico e das lógicas de consumo no espaço público pode ser excludente em relação a outras atividades - mais funcionais, simbólicas ou primordiais - e outros utilizadores. A "turistificação" ou a tematização de determinados espaços públicos serão exemplos destes fenómenos ${ }^{23}$ : “As space is stripped of its emotional

\footnotetext{
22 Podendo inserir-se nesta categoria também os comerciantes.

${ }^{23}$ Processos de transformação dos espaços urbanos baseados e dominados por actividades turísticas (GravariBarbas y Guinand 2017), ou outros "temas urbanos" - patrimonialização, espaços de lazer ou de consumo -
} 
and cultural value, which is developed only through people's use over time, it is treated as a mere commodity" (Madanipour 2003).

Por fim, os atores utilizadores, ou destinatários da produção do espaço público, são atores com menor poder no processo, mas com interesse e alguma influência. Em geral são os que melhor conhecem e mais usufruem do espaço público, pela utilização direta e pelos benefícios (ou malefícios) daí decorrentes. Paradoxalmente são aqueles que frequentemente são menos integrados nos processos de produção, embora sejam os mais relevantes para a identificação de necessidades e direitos (Carr et al. 1992) que o espaço público deve garantir. $O$ não atendimento destes, ou a sua restrição, podem evidenciar fenómenos de exclusão ou segregação. Através do seu poder de reivindicação têm a capacidade de produzir opinião e protestar, através da identificação de espaços com necessidades de intervenção, ações de participação pública ou ações de protesto.

É ainda de referir que os espaços públicos também são moldados pela ausência de reivindicações e interesse por parte dos atores, do qual é exemplo a retirada da esfera pública (Madanipour 2010), com consequências para a degradação do espaço.

Se a ação de cada ator é condicionada pelos seus interesses no espaço público, a interseção destes não será sempre livre de conflito. Os interesses divergentes podem vir, por exemplo da própria Administração (diferentes estratégias nos vários níveis de governo local, central, sectorial, etc.), ou do impacto das ações de atores económicos na garantia dos direitos de todos os utilizadores. Veja-se como exemplo as discussões relativas à privatização do espaço público (Zukin 1998) e em torno do conceito de publicness, a partir de espaços públicos tratados e geridos por entidades privadas, focados em alguns grupos de utilizadores e privilegiando o retorno económico, diminuindo a dimensão pública dos próprios espaços.

A intervenção de cada ator no espaço público é ainda motivada pelas aspirações e pela capacidade de resposta do espaço público aos seus objetivos. Para cada ator haverá diferentes conceções de qualidade de espaço, em consequência das suas necessidades e das motivações distintas que têm sobre as funcionalidades do espaço ${ }^{24}$. Assim estes podem ter diferentes interpretações sobre a qualidade do espaço e sobre o seu desenho, como forma

são muitas vezes orientados pelo consumo comercial (Zukin 2006) e tendem a reduzir a diversidade de usos e dinâmicas no espaço público, podendo excluir ou afastar outros tipos de utilizadores.

${ }^{24}$ Por exemplo o interesse dos residentes no estacionamento como garantia de acessibilidade e comodidade; o interesse dos comerciantes no acesso ao seu estabelecimento (seja viário, pedonal, ou através do estacionamento); o interesse dos promotores nos espaços verdes e de utilização coletiva como forma de valorização do seu produto e pela capacidade atrativa que tem, contribuindo para a obtenção de lucro. 
de gerar atração, de promover a notoriedade e uma imagem positiva da cidade; ou ainda sobre a sua funcionalidade e características, resultantes das várias tipologias e elementos que o compõem, sendo para Carmona et al., (2008) poucos os atores que têm como principal motivação a qualidade global do espaço.

Os vários atores intervenientes na produção do espaço público possuem relações de dependência entre si, ainda que a natureza dessa relação não seja sempre a mesma. Como exemplo, é possível considerar que os atores políticos influenciam a ação dos atores técnicos através da tomada de decisão no planeamento e projetos de intervenção. Estas decisões terão repercussões na ação dos atores económicos (como os investidores ou os promotores imobiliários), que veem a sua ação condicionada por essa tomada de decisão. Já a ação dos atores técnicos, dos concessionários e operadores de infraestruturas e serviços coletivos e das entidades gestoras de equipamentos na regulação da ocupação do espaço, influencia a utilização que é feita do espaço público. Numa outra perspetiva, há ainda que considerar a pressão feita pelos atores económicos e utilizadores sobre os atores políticos, através do contributo no financiamento e execução, dos mecanismos de voto, ou ações de protesto e outras formas de participação pública.

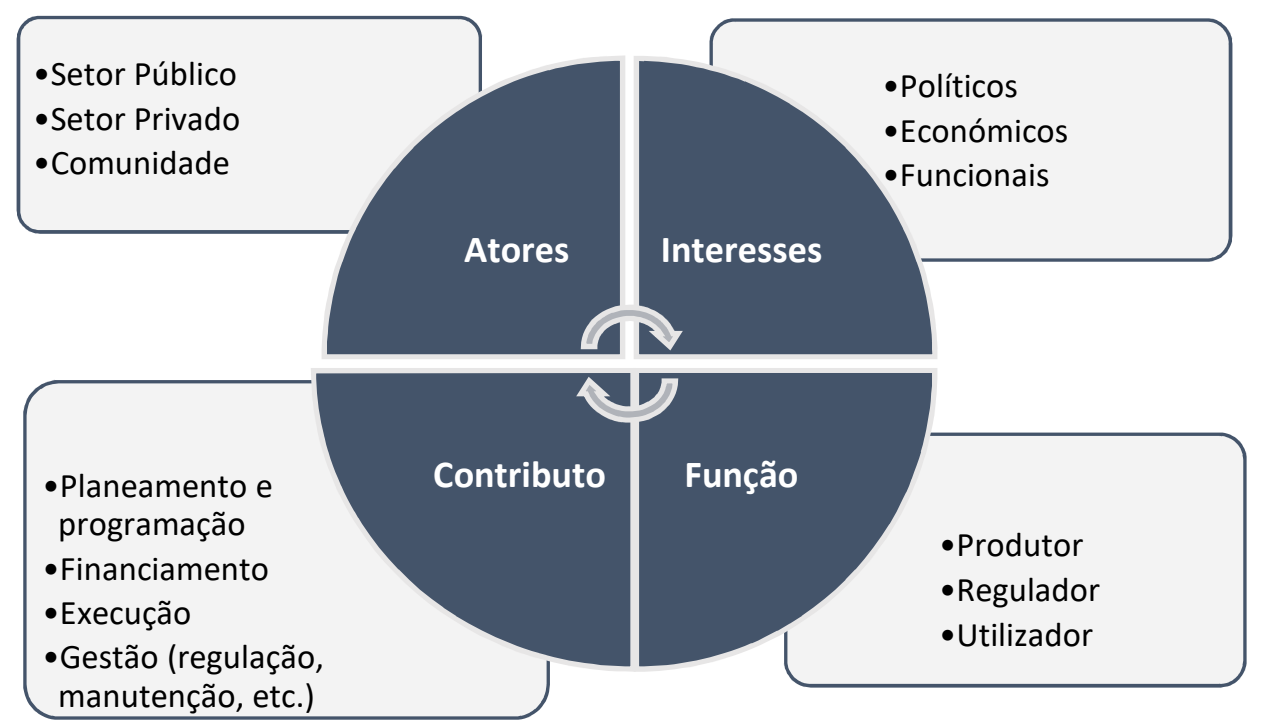

Figura 6. A complexidade da governança na produção de espaço público

Numa analogia com o processo de urbanização, que pode ser visto como "um jogo complexo onde vários jogadores intervêm através de instrumentos e ferramentas 
próprias"(Cavaco 2009), a produção do espaço público envolve um conjunto de fatores que a complexifica (figura 6). Para além dos diferentes papéis assumidos pelos vários atores, também a influência e importância que cada ator tem na produção e na gestão do espaço público varia com (1) a natureza da intervenção; (2) a relação que estabelece com o espaço, ou seja, a forma como o utiliza ou beneficia dele; (3) a sua capacidade de intervenção tendo em conta os recursos que tem disponíveis; (4) e pela própria dimensão da produção e da gestão a que nos referimos (planeamento/programação, execução, manutenção, regulação, etc.).

A multiplicidade de interesses e atores reclama por isso, estruturas e formas de concertação, que incluam mobilização, participação e "empoderamento" (Friedmann 1987).

\section{Os desafios na prática de produção e gestão do espaço público}

O capítulo seguinte centra-se nos desafios que se colocam à prática de produção e gestão do espaço público. Esta identificação decorre não só dos resultados da análise do caso de estudo - feita a partir da leitura sobre a organização do espaço público nos serviços municipais, da identificação dos principais instrumentos e contextos de produção de espaço público no município e dos atores-chave intervenientes - e dos testemunhos recolhidos em entrevista aos técnicos municipais e profissionais liberais, como também da análise do quadro normativo para a produção de espaço público e da heterogeneidade e relações entre os atores envolvidos, anteriormente apresentadas para o contexto português.

Conscientes das especificidades territoriais do município de Almada e da sua evolução, considera-se que muitos dos desafios aqui enumerados resultam de questões transversais ao território nacional, visto estarem diretamente relacionadas com a estrutura organizativa da Administração Pública, com o sistema de planeamento português e com os atores que, de forma global, intervêm na produção e gestão do espaço público. Neste sentido, considera-se que parte destes desafios possam ser encontrados noutros casos portugueses, ainda que a sua inserção em contextos territoriais diferentes possa conduzir a consequências e resultados finais distintos. 
A apresentação dos desafios será aqui organizada de uma forma temática, identificando-se, sempre que possível e pertinente, os desafios mais genéricos, que decorrem da prática nacional e dos testemunhos recolhidos, e os que se consideram ser mais específicos do caso de Almada.

A partir do quadro normativo português para a produção de espaço público, verifica-se a multiplicidade de diplomas legais, regulamentos e instrumentos urbanísticos que incidem sobre a produção e gestão do espaço público, promovidos por diferentes atores. Esta dispersão da normativa da produção está associada à fragmentação das políticas e dos seus componentes em setores distintos, assistindo-se a uma setorização das políticas e das ações sobre o espaço público, não só entre os vários níveis de governabilidade da Administração Pública, como também dentro da própria gestão municipal, onde se verifica uma prática de separação de temáticas nos respetivos departamentos ${ }^{25}$.

A estrutura hierárquica e organizacional da Administração Pública e dos seus serviços pode ser, segundo as opiniões recolhidas, um dos grandes desafios à produção de espaço público, na medida em que dificultam a obtenção de uma solução para um determinado território, devido ao olhar setorial de cada entidade sobre o mesmo território (E2). No caso específico de Almada ficou patente que esta dificuldade de conciliação de interesses em áreas com múltiplas jurisdições condiciona por vezes a ação do município, que ficará dependente das condições impostas por entidades hierarquicamente superiores (com opiniões muitas vezes contraditórias) e pelas servidões e condicionamentos dos instrumentos supramunicipais (E2).

A (difícil) conciliação de interesses, mesmo dentro dos próprios serviços municipais, foi um dos problemas transversais mencionados nos testemunhos recolhidos. Esta decorre do olhar setorial que cada departamento tem na abordagem de intervenção sobre um determinado espaço, o que, relacionado com a falta de coordenação entre os vários departamentos e uma prática setorizada do diagnóstico de necessidades de intervenção (E6), parece apontar para a setorização do espaço público nos serviços municipais. Contudo,

\footnotetext{
${ }^{25}$ Com base no exemplo da Organização dos Serviços Municipais de Almada (Despacho n.o 2485a/2015), o planeamento, execução e gestão do espaço público encontra-se repartido entre os departamentos de Planeamento Urbanístico, de Administração Urbanística, das Obras Municipais, do Ambiente e Mobilidade, da Salubridade e Espaços Verdes, da Rede Viária, Manutenção e Transportes, de Intervenção Social e Habitação e entre as divisões de Requalificação e Revitalização Urbana e Espaço Público, de Fiscalização e de Qualificação de Mercados e Serviços Urbanos.
} 
também se verificou uma perspetiva contrária, em que a "departamentalização" do espaço público é vista como uma condição necessária face à diversidade de elementos que o compõem ${ }^{26} \mathrm{e}$ à diversidade de interações com outros sistemas urbanos, que exigem conhecimentos especializados em determinadas áreas (E1). Esta relação com outros sistemas urbanos, pelas suas diferentes finalidades, "torna difícil conseguir-se uma interação benéfica entre todos" (E4), reconhecendo-se que a sobreposição de uns perante outros condiciona uma visão integrada sobre o sistema espaço público.

Esta diversidade de elementos é genericamente apontada pelos técnicos e profissionais entrevistados como um dos principais desafios na gestão e manutenção do espaço pela elevada exigência de recursos - financeiros, técnicos e humanos - e pelo esforço de coordenação necessário entre os vários atores com responsabilidades sobre determinadas áreas de intervenção, como os concessionários e operadores de infraestruturas e serviços coletivos.

O crescente número de atores envolvidos na produção e gestão do espaço público é assim reconhecido como um desafio transversal à sua produção e gestão. Nesta lógica, também a complexidade de relações entre eles, a diversidade de interesses - por exemplo o conflito entre os benefícios económicos e os benefícios ambientais e sociais de um espaço público (E3) - e a dificuldade na gestão das suas expectativas tornam difícil trabalhar o espaço público como um sistema (E3).

Ainda no que diz respeito à heterogeneidade de atores na produção e gestão de espaço público, o envolvimento dos utilizadores no processo de produção e gestão foi uma das preocupações apontadas nas entrevistas realizadas. Na opinião dos técnicos, a comunidade é fundamental quer na identificação das suas expectativas e consequentes necessidades de intervenção no espaço público, quer no apoio que podem prestar à atuação municipal na gestão do espaço. Contudo, revelam que, em geral, a participação pública no planeamento e na gestão urbana não está a ser bem conduzida, revelando a necessidade de novas práticas e de novas metodologias que a tornem mais eficaz (E4).

A partir da análise do caso de estudo de Almada foi possível verificar que o facto da intervenção no espaço público ser quase sempre uma intervenção pontual, concretizada

\footnotetext{
${ }^{26}$ Desde espaços verdes, largos e praças a ciclovias, percursos pedonais e infraestruturas viárias, etc.
} 
através de projetos específicos para o efeito, dificulta por vezes a concretização de estruturas sistémicas e extensivas, e o consequente aproveitamento do seu carácter estruturante, pois nem sempre estão afetos os recursos necessários para a sua execução. Por exemplo, estruturas urbanas contínuas como a rede ciclável municipal, encontram-se enquadradas politicamente nos objetivos da Administração (como forma de concretização das políticas ambientais, de mobilidade suave, de promoção da atividade física, etc.) e até mesmo na normativa de produção de espaço público, mas a sua execução é condicionada pela incapacidade executória da Administração Local, pela dificuldade de integração no território e pela falta de recursos financeiros. Neste sentido, estas ficam muitas vezes ora nas mãos dos privados (com obrigatoriedade de a incluir nos novos projetos de loteamento), ora à espera de projetos nos quais se possam inserir.

Numa ótica mais global, as dificuldades de execução do espaço público estão também associadas às dificuldades de implementação dos planos e aos diferentes ritmos do processo de planeamento (E2) e à incapacidade negocial da Administração Local, perante o interesse económico e especulativo de curto prazo dos atores com recursos financeiros para a execução (E6), como os promotores imobiliários. Estas dificuldades estão também relacionadas com a incapacidade de intervenção da Administração Local que, face à escassez de recursos se vê obrigada a procurar outros mecanismos de intervenção, como a delegação de competências aos privados ou a procurar investidores para intervir no território, concretizando as propostas de plano ${ }^{27}$, tal como se verificou no caso de Almada.

A intervenção sobre os espaços existentes ou em territórios urbanisticamente comprometidos, como as áreas de ocupação ilegal ou os núcleos históricos, é uma das dificuldades observadas na análise deste caso de estudo. Estes são territórios que pelas suas características possuem problemas ao nível do espaço público - limitação de espaço para intervenção, indefinição de limites entre o público e o privado - que dificultam o ajuste aos novos paradigmas e exigências da sociedade e a atualização de certos parâmetros urbanísticos definidos por lei (E2).

\footnotetext{
${ }^{27}$ Ilustradas pela integração dos percursos cicláveis previstos na rede ciclável nas operações de loteamento promovidas pelos particulares e pela abertura de concursos para a concretização de Planos de Pormenor ou de Urbanização.
} 
Numa lógica mais transversal, a aplicação direta, descontextualizada e pouco flexível (E7) de índices e indicadores exigidos nas normativas nacionais e europeias, "apenas para cumprir regulamentos, sem qualquer objetivo de diagnóstico ou de apoio à decisão" (E4) e sem atender às especificidades de cada território, pode igualmente considerar-se um problema na produção do espaço público, que poderá condicionar o produto final e a sua utilização.

Numa outra dimensão, também são identificados problemas ao nível da manutenção do espaço público, condicionada entre outros aspetos pela falta de recursos e pela falta de clareza na atribuição de funções aos vários atores intervenientes. Ora veja-se o exemplo de uma área do município de Almada, projetada pela Administração Central através do Plano Integrado de Almada (elaborado pelo Fundo de Fomento para a Habitação em 1973), área ainda hoje sob responsabilidade dos órgãos do governo central, uma vez que não foi objeto de ratificação do Plano Diretor Municipal de Almada em 1997, ficando assim excluída do plano e da alçada da Câmara Municipal. Por isso, as responsabilidades sobre a sua gestão são ainda dúbias, embora se assista a uma progressiva transferência de poder e das competências relativas ao território para a Administração Local. A falta de clarificação de competências causa problemas ao nível da manutenção e

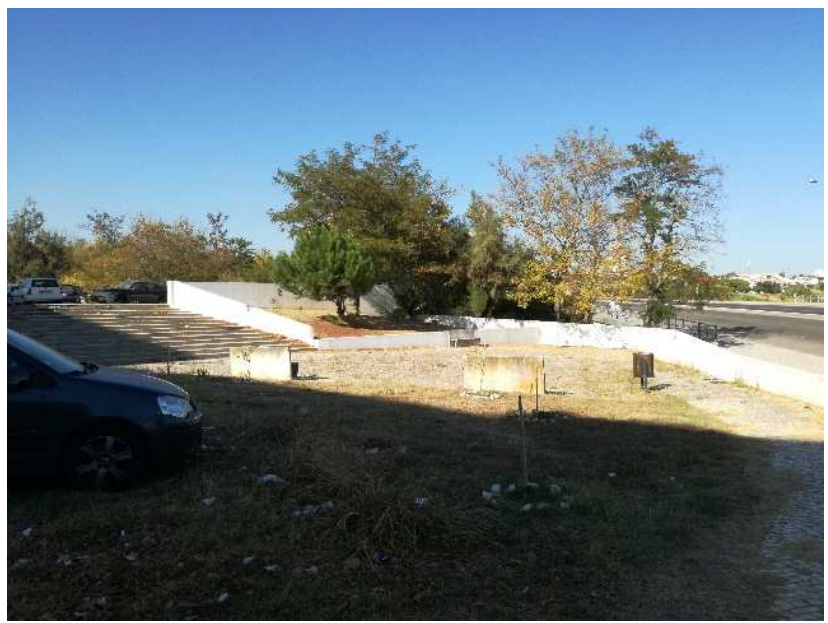

Figura 7. Área de intervenção do Plano Integrado de Almada. Fonte própria. consequente declínio e degradação dos espaços (figura 7).

Ora, a essa progressiva transferência de poderes e de competências vão estar associadas as dificuldades de manutenção de espaços que não foram produzidos pelo município, mas cujas competências de gestão recaem sobre a sua responsabilidade, tal como foi apontado no caso de Almada. Esta questão aplica-se também aos inúmeros espaços produzidos pelos privados (obras de infraestruturas nas operações de loteamento ou em grandes empreendimentos comerciais ou turísticos), criando dificuldades pela limitação de recursos da autarquia (E2). 


\section{Considerações finais sobre algumas problemáticas da produção do espaço público}

Considerando o quadro da produção de espaço público em Portugal e os desafios que na prática se lhe colocam, constata-se que este é um processo que envolve um vasto conjunto de fatores que o complexificam. Tudo isto se reflete na condição do espaço público atualmente, que muitos consideram que evidencia um somatório das partes, fragmentado e descontínuo (Francisco 2005; Brandão et al. 2017; Coelho 2016).

Apesar das suas especificidades, o caso de estudo de Almada ilustra a multiplicidade de questões relacionadas com a produção e na gestão do espaço público, tendo-se verificado não só a fragmentação normativa e consequente fragmentação espacial que lhe estão associadas, como também os problemas de gestão decorrentes da forma de produção do espaço e resultantes da escassez de recursos, dos conflitos de interesses e das relações entre atores.

Estas dificuldades aqui apresentadas são apenas alguns exemplos, aos quais se podem associar outras problemáticas mais genéricas, relacionadas com a prática urbanística portuguesa. Assim, considera-se que a condução do processo de urbanização a partir da iniciativa privada, através da figura da operação de loteamento ou mesmo da construção ilegal, a gestão urbanística feita a partir do Plano Diretor Municipal, o carácter rígido, vinculativo e inoperativo das figuras de planeamento, a incapacidade e falta de proatividade da Administração Pública (Carvalho 2003; Portas, Domingues \& Cabral 2011; Travasso \& Valle 2014) e a falta de critérios qualitativos nas áreas de cedência para espaço público previstas na legislação (Silva 2014) influenciaram a forma como o espaço público tem sido produzido em Portugal, refletindo-se no exemplo de Almada.

Como consequência desta prática e do próprio sistema de planeamento português, o espaço público é resultante da fragmentação do espaço urbano, do défice de estrutura e continuidade, da tomada de decisão em desconhecimento dos efeitos no tecido urbano e da ausência de diálogo e troca de ideias durante a conceção (Francisco 2005). 
Embora com o reconhecimento da importância e potencial do espaço público, através das opiniões recolhidas ficou patente que as dificuldades de execução que lhe estão associadas, a falta de entendimento como um elemento sistémico, a visão cética sobre o espaço público como um projeto pontual e a constante atribuição de responsabilidades à Administração Local, condiciona o seu desempenho nos papéis que pode ter no sistema urbano.

Perante o quadro normativo português, a identificação dos atores intervenientes e a análise do caso de estudo, considera-se que a produção de espaço público pode ser influenciada por vários fatores interrelacionados:

- Os instrumentos e ferramentas existentes para a produção e execução de espaço público (i.e., a normativa da produção), a legislação que regula o planeamento e ordenamento do território e as políticas que conduzem a intervenção no espaço urbano;

- A disponibilidade política para a intervenção, ou seja, o papel do espaço público na estratégia política de intervenção e a relevância que lhe é atribuída pelos decisores. Aqui, há que considerar o aproveitamento de oportunidades políticas, de financiamento e da concretização de projetos como fundamental para a produção do espaço;

- A disponibilidade de recursos e meios para a intervenção, sejam recursos técnicos, financeiros, a propriedade do solo, ou a capacidade executória dos atores intervenientes;

- As competências, responsabilidades e interesses dos atores envolvidos, influenciados pela capacidade da Administração Pública e de ação dos privados.

Estes aspetos identificados decorrem da estrutura de análise, em particular da visão de alguns atores com papéis específicos neste contexto (produtores e reguladores). Assim, reconhece-se a importância de alargar o estudo sobre a produção e gestão do espaço público a outros atores relevantes, nomeadamente os utilizadores, incluindo assim as suas perspetivas nos desafios e problemas a identificar. Da mesma forma, uma atenção a outras 
dimensões da produção - apropriação e vivência, interações sociais, etc. - trariam igualmente dimensões de análise e de reflexão pertinentes ${ }^{28}$.

Esta reflexão sobre a produção e a gestão do espaço público, contextualizada no caso português, demonstra a fragmentação, diversidade e complexidade que pode existir na sua produção e gestão. A partir do exemplo de Almada verifica-se que estas não são consideradas num processo integrado, mas sim o resultado do somatório de várias políticas, contextos e da ação de diversos atores, cuja atuação ocorre a múltiplas escalas e em diferentes níveis de governação.

Embora se pareça estar a caminhar para uma nova visão sobre o espaço público, através da sua crescente valorização no contexto urbano e do aparecimento de alguns documentos e orientações específicas (como as cartas municipais de espaço público), torna-se claro com esta reflexão quais as dificuldades que podem estar associadas a esta norma de produção, pondo em questão qual será o papel pretendido para o espaço público no sistema urbano.

Perante as problemáticas verificadas, será este o modelo de produção e de gestão de espaço público mais adequado para dar resposta aos desafios atuais? Este modelo permite que o espaço público cumpra o seu papel de elemento estruturante no sistema urbano? Estas são questões que se deixam em aberto e que veem neste artigo um ponto de abertura para a sua discussão.

\section{Agradecimentos}

As autoras agradecem o apoio da Fundação para a Ciência e a Tecnologia (FCT) através do projeto PTDC/ECM- URB/2162/2014 e do CERIS, Investigação e Inovação em Engenharia Civil para a Sustentabilidade através da bolsa de investigação com referência UID/ECl/04625/2013.

\footnotetext{
${ }^{28}$ Como a multidimensionalidade do espaço público, a diversidade de papéis que pode assumir no contexto urbano ou o contexto socioeconómico e físico-espacial onde este se situa.
} 


\section{Referências bibliográficas}

ASCHER, F. Les nouveaux principes de l'urbanisme. La Tour-d'Aigues: Editions de l'Aube, 2001. ISBN 2-87678992-2 978-2-87678-992-0.

BORJA, J. y MUXÍ, Z. El espacio público: ciudad y ciudadanía. Barcelona: Electa, 2003. ISBN 84-8156-343-9.

BRANDÃO, A., BRANDÃO, P. y FERREIRA, A. The Role of Public Space Systems on Urban Transformation: A Review on Lisbon South Bank Regeneration Process. En: E.M. da COSTA, S. MORGADO y J. CABRAL (eds.), AESOP Annual Congress "Spaces of Dialog For Places of Dignity: Fostering the European Dimension of Planning», 2003. Lisboa: Universidade de Lisboa, pp. 796-806.

BRENNER, N. New state spaces: urban governance and the rescaling of statehood. Oxford: Oxford University Press, 2004. ISBN 9780199270064.

CARMONA, M., HEATH, T., OC, T. y TIESDELL, S. Public Places - Urban Spaces: The Dimensions of Urban Design. Oxford; Boston: Architectural Press, 2003. ISBN 0750636327.

CARMONA, M., MAGALHÃES, C. de y HAMMOND, L. Public space: The Management Dimension. London; New York: Routledge, 2008. ISBN 0415396492.

CARR, S., FRANCIS, M., G.RIVLIN, L. y M. STONE, A. Public space. Cambridge: Cambridge University Press, 1992. ISBN 0521351480.

CARVALHO, J. Ordenar a Cidade. Coimbra: Quarteto, 2003.

CAVACO, C.S.R.G. Formas de habitat suburbano. Tipologias e modelos na área metropolitana de Lisboa. S.I.: Tese de Doutoramento em Arquitectura, Faculdade de Arquitectura da Universidade Técnica de Lisboa, 2009.

COELHO, R. Desígnios e formas do espaço público na cidade contemporânea: Notas para pensar o projecto do espaço público na construção da cidade portuguesa. Revista Iberoamericana de Urbanismo, 2014, $n^{\circ} 11$, pp. 7998.

C COELHO, R. O espaço público na construção da cidade portuguesa recente: três décadas em balanço Introdução antecedentes cidade portuguesa contemporânea. Revista de Geografia e Ordenamento do Território (GOT), 2016, n. 9 (junho). Centro de Estudos de Geografia e Ordenamento do Território, pp. 91-112. DOI dx.doi.org/10.17127/got/2016.9.005 \%0D.

FORTUNA, C., FERREIRA, C. y ABREU, P. Espaço público urbano e cultura em Portugal. Revista Crítica de Ciências Sociais. 1999, no 52/53, pp. 85-117.

FRANCISCO, M.D. Espaço Público Urbano: Oportunidade de Identidade Urbana Participada. Actas do $X$ Colóquio Ibérico de Geografia, 2005. Évora: Universidade de Évora.

FRIEDMANN, J. Planning in the Public Domain: From Knowledge to Action. Princeton: Princeton University Press, 1987. ISBN 0-691-02268-2.

FRIEDMANN, J. Place and Place-Making in Cities: A Global Perspective. Planning Theory \& Practice, 2017, vol. 11, n.o 2, pp. 149-165. DOI 10.1080/14649351003759573

GRAVARI-BARBAS, M. y GUINAND, S.. Tourism and Gentrification in contemporary metropolises international perspectives. New York, NY: Routledge, 2017. ISBN 9781138642782.

HEALEY, P. Transforming Governance: Challenges of Institutional Adaptation and a New Politics of Space. European Planning Studies, 2006, vol. 16, no. 3, pp. 299-320. DOI 10.1080/09654310500420792.

HERCE, M. El Negocio del territorio. Evolución y Perspectivas de La Ciudad Moderna. Madrid: Alianza Editorial, 2013. ISBN 84-206-7449-4.

JACOBS, J. The Death and Life of Great American Cities. New York: Random House, 1961. ISBN 978-0-67974195-4

LEFEBVRE, H. La Production de L'espace. Paris: Anthropos, 1974.

LYNCH, K. The Image of the City. Cambridge, Massachusetts: MIT Press, 1960. ISBN 978-0-262-62001-7.

MADANIPOUR, A. Public and Private Spaces of the City. London ; New York: Routledge, 2003. ISBN 978-0-415- 
25629-2.

MADANIPOUR, A. Whose Public Space? International case studies in urban design and development. Taylor \& Francis, 2010. ISBN 9780203860946.

MCINDOE, G., CHAPMAN, R., MCDONALD, C., HOLDEN, G., HOWDEN-CHAPMAN, P. y SHARPIN, A.B. The Value of Urban Design The economic, environmental and social benefits of urban design. Wellington, New Zealand: Ministry for the Environment, 2005.

MOTA, J.C.B. Planeamento Do Território : Metodologias, Actores E Participação. Tese de Doutoramento em Ciências Sociais, Universidade de Aveiro, 2013.

PEREIRA, M. Cultura de Planeamento e Governação: Contributos para a coesão territorial. Actas $15^{\circ}$ Congresso da APDR, 2009. Cabo Verde, Cabo Verde: APDR, pp. 816-838. ISBN 978-989-96353-0-2.

PINTO, A.J. Coesão urbana: o papel das redes de espaço público. Tese de Doutoramento em Espaço Público e Regeneração Urbana, Universitat de Barcelona, 2015.

PORTAS, N. Conceitos de Desenvolvimento Urbano. Os Tempos das Formas. Vol. I: A Cidade Feita e Rarefeita. Guimarães: Escola de Arquitectura da Universidade do Minho, 1987, pp. 105-119

PORTAS, N. Da Estratégia ao Projecto. Os Tempos das Formas. Vol. II: A Cidade Imperfeita e a Fazer. Guimarães: Escola de Arquitectura da Universidade do Minho, 1998, pp. 87-101.

PORTAS, N., DOMINGUES, Á. y CABRAL, J. Políticas Urbanas II: Transformações, Regulação e Projectos. Lisboa: Fundação Calouste Gulbenkian, 2011.

SEIXAS, J. A Cidade na Encruzilhada. Repensar a Cidade e a sua Política. Porto: Edições Afrontamento, 2013.

SILVA, A.F. A Dotação do Espaço Público no Planeamento Urbano. Dissertação para obtenção do grau de Mestre em Planeamento e Projeto Urbano, Faculdade de Engenharia da Universidade do Porto, 2014.

TRAVASSO, N. y VALLE, D.C. Urbanization in the Ave Valley region: more than a sum of building projects? En: V. OLIVEIRA, P. PINHO, L. BATISTA, T. PATATAS y C. MONTEIRO (eds.), Our Common Future in Urban Morphology [en línea]. Porto: FEUP, 2014, pp. 1502-1520. DOI 978-972-99101-6-6.

UCLG. Public Space Policy Framework: by and for local governments. UCLG, 2016.

UN-HABITAT. Global Public Space Toolkit: From Global Principles to Local Policies and Practice. Nairobi (Kenya): UN-Habitat, 2015. ISBN 978-92-1-132656-7.

ZUKIN, S. Politics and aesthetics of public space: The "American» model. En: P. SUBIRÓS (ed.), Ciutat real, ciutat ideal. Significat i funció a l'espai urbà modern. Barcelona: Centre de Cultura Contemporània de Barcelona, 1998.

ZUKIN, S. The cultures of cities. Cambridge: Blackwell Publishers, 2006. 


\section{Anexo 1 - Entrevistas realizadas}

\begin{tabular}{|c|l|}
\hline \multicolumn{2}{|l|}{ Listagem das entrevistas } \\
\hline E1 & Técnico Municipal na Câmara Municipal de Almada \\
\hline E2 & Técnico Municipal na Câmara Municipal de Almada \\
\hline E3 & Técnico Municipal na Câmara Municipal de Lisboa \\
\hline E4 & Técnico Municipal na Câmara Municipal de Santo Tirso \\
\hline E5 & Técnico Municipal na Câmara Municipal do Montijo \\
\hline E6 & Profissional Liberal - Arquiteto Urbanista \\
\hline E7 & Profissional Liberal - Urbanista e Engenheiro de Transportes \\
\hline E8 & Profissional Liberal - Engenheiro do Território e Urbanista \\
\hline
\end{tabular}

